\title{
Baseline elevated Lp-PLA2 is associated with increased risk for re-stenosis after stent placement
}

\author{
Dongdan Zheng ${ }^{1}$, FanFang Zeng ${ }^{2}$, Anping Cai ${ }^{3}$, Huocheng Liao ${ }^{4}$, Ling Liư ${ }^{4}$ Ruofeng Qiư ${ }^{1}$ Rulin Xu', \\ Chun Xiao ${ }^{4^{*}}$ and Weiyi Mai ${ }^{1^{*}}$
}

\begin{abstract}
Background: Lipoprotein associated phospholipase A2 (Lp-PLA2) is a novel biomarker for cardiovascular risk prediction. Whether increased LP-PLA2 level is associated with re-stenosis after stent-placement is unclear.

Methods: Totally 326 participants eligible for stent-placement were enrolled and divided into two groups according to baseline Lp-PLA2 levels (named normal and elevated groups). Baseline characteristics and clinical outcomes were compared between normal and elevated groups. The relationships between Lp-PLA2 and other risk factors with re-stenosis were evaluated.

Results: Only the between-group difference of Lp-PLA2 was significant $(123.2 \pm 33.6 \mathrm{ng} / \mathrm{mL}$ vs $336.8 \pm 85.4 \mathrm{ng} / \mathrm{mL}$, $\mathrm{P}<0.001$ ) while other demographic and clinical characteristics between these two groups were comparable. Approximately $55.1 \%$ and $58.5 \%$ of participants in normal and elevated groups presented with acute coronary syndrome, and the percentage of tri-vessels stenoses was significantly higher in elevated group (40.8\% vs $32.1 \%$, $P=0.016$ ). Nearly $96.0 \%$ and $94.0 \%$ of participants in normal and elevated LP-PLA2 groups were placed with drugeluting stents, and the others were with bare-metal stents. After 1 year's follow-up, the incidence of clinical endpoints was comparable (13.3\% vs $15.4 \%, \mathrm{P}=0.172)$. Nevertheless, the incidence of re-stenosis was marginally higher in elevated LP-PLA2 group (8.5\% versus 4.6\%, P = 0.047). With multivariate analysis, after adjustment for other risk factors, Lp-PLA2 remained an independent predictor for re-stenosis with a hazard ratio of 1.140. No synergistic effect between Lp-PLA2 and other risk factors for re-stenosis was found.
\end{abstract}

Conclusion: Increased Lp-PLA2 level is associated with an increased risk of re-stenosis. Lp-PLA2 assessment may be useful in predicting subjects who are at increased risk for re-stenosis.

Keywords: Lipoprotein associated phospholipase A2, Coronary artery disease, Percutaneous coronary intervention

\section{Introduction}

Atherosclerotic cardiovascular diseases (CAD), in terms of coronary heart disease (CHD), ischemic stroke and peripheral vascular disease, are still the leading causes of morbidity and mortality worldwide [1,2]. Currently, it has been well documented that inflammatory reaction plays critical roles on the initiation and progression of atherosclerosis and CHD [3,4]. Lipoprotein associated

\footnotetext{
*Correspondence: wymai@hotmail.com; HuizhouXiaoc@163.com 'Department of Cardiology, The First Affiliated Hospital of Sun Yat-sen University, 58 Zhongshan Road 2, Guangzhou 510080, China

${ }^{4}$ Department of Cardiology, The 3rd People's Hospital, Huizhou 516000, China

Full list of author information is available at the end of the article
}

phospholipase A2 (Lp-PLA2), an enzyme excreted by inflammatory cells such as macrophages, nowadays has raised many concerns owing to its highly sensitive and specific features for vascular inflammation $[5,6]$. Previously, some basic research show that Lp-PLA2 plays casual role on atherosclerosis and inhibiting Lp-PLA2 ameliorates vascular inflammation and deters atherosclerosis progression $[7,8]$. Furthermore, some epidemiological studies and meta-analyses also consistently show that increased plasma level of Lp-PLA2 is associated with increased risk of cardiovascular events [9-12]. In light of these findings, Lp-PLA2 has been recognized

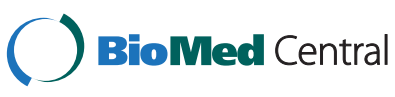

(c) 2014 Zheng et al.; licensee BioMed Central Ltd. This is an Open Access article distributed under the terms of the Creative Commons Attribution License (http://creativecommons.org/licenses/by/2.0), which permits unrestricted use, distribution, and reproduction in any medium, provided the original work is properly credited. The Creative Commons Public Domain Dedication waiver (http://creativecommons.org/publicdomain/zero/1.0/) applies to the data made available in this article, unless otherwise stated. 
as a novel and important predictor for cardiovascular risk assessment $[13,14]$.

Currently, percutaneous coronary intervention (PCI) is the preferred choice for patients with acute myocardial infarction or with significant coronary artery stenoses. Nevertheless, despite dual anti-platelet and intensive statins therapy, the incidence of re-stenosis after stent placement is still high $[15,16]$. Therefore, identifying a specific and sensitive biomarker for predicting re-stenosis is of paramount importance. Owing to the significant and unequivocal implications of Lp-PLA2 on the initiation and progression of atherosclerosis and $\mathrm{CAD}$, we speculated that increased plasma level of Lp-PLA2 at baseline might contribute to re-stenosis in patients with stent placement. If finally corroborated, we believed that in the future lowering Lp-PLA2 level with its specific antagonist would definitely reduce the risk of re-stenosis and doubtless improve the outcomes of patient with CAD.

\section{Method}

\section{Study population and protocol}

Current study was started in September of 2011 and ended in September of 2012. All participants were without previous history of atherosclerotic cardiovascular diseases. After angiographic evaluation, patients diagnosed as significant $\mathrm{CHD}$ and eligible for stent-placement were enrolled after written informed consent was obtained. Baseline demographic and clinical characteristics including traditional risk factors and laboratory results were collected. All participants were followed-up for 1 year via outpatient visit or telephone contact for detecting the first episode of pre-specified clinical outcomes.

\section{Routine laboratory parameters and Lp-PLA2 measurements}

Fasting blood samples were drawn by veni-puncture in the morning. Measurements of routine laboratory parameters in current study were consistent to previous study report unless otherwise mentioned [17]. Plasma level of Lp-PLA2 was detected with commercial LpPLA2-ELISA kit (PLAC test; supplied by dia Dexus Inc, South San Francisco, California). All the procedures were performed according to the manufactures' instructions. Based on previous recommendation [18], plasma LpPLA2 level less than $200 \mathrm{ng} / \mathrm{mL}$ is defined as within normal range, while equal or higher than $200 \mathrm{ng} / \mathrm{mL}$ is recognized as elevation. All participants were divided into two groups on the basis of the plasma level of Lp-PLA2.

\section{Clinical outcomes assessments post-stent placement}

Clinical outcomes were defined as cardiovascular related death, nonfatal myocardial infarction, nonfatal ischemic stroke, and re-stenosis (> 50\% stenosis of target lesion) by angiographic examination. Comparisons of clinical outcomes were conducted between groups with normal or elevated plasma levels of Lp-PLA2 during the 1 year's follow-up. Risk factors for re-stenosis after 1 year's followup were also evaluated.

\section{Statistical analysis}

Continuous variable was presented as mean \pm SD or median appropriately, and compared by the Student's t-test when data was normally distributed, otherwise compared by Wilcoxon rank-sum test. Categorical data was showed as percentage and compared by $\chi^{2}$ test. Univariate and multivariate Cox proportional hazard regression were used to evaluate the associations between baseline demographic and clinical characteristics and incidence of re-stenosis after 1 year's follow-up. Variables with $\mathrm{p}$ values $<0.10$ were entered into multivariable model and variables with $\mathrm{p}$ values $<0.10$ were stayed in the model. Synergistic effects between other risk factors and LpPLA2 for re-stenosis were also evaluated. Statistical analyses were performed by using SPSS software version 16.0 (SPSS, Inc., Chicago, Illinois). A value of $\mathrm{p}<0.05$ was considered significant.

\section{Results}

\section{Baseline demographic and clinical characteristics of} participants

A total of 326 participants were enrolled in our current study, and accordingly, were divided into two groups on the basis of baseline plasma levels of Lp-PLA2. As presented in Table 1, only the difference of plasma LpPLA2 level between the normal and elevated groups achieved statistical significance. Male patients were predominant and accounted for $66.3 \%$ and $65.4 \%$ in each group, respectively. More than $50.0 \%$ of patients in each group have a history of hypertension. Each group had nearly $20 \%$ of patients with diabetes mellitus, and 29 (85.3\%) patients in normal Lp-PLA2 group and 20 (83.3\%) patients in elevated Lp-PLA2 group were treated with insulin and the rest $(14.7 \%$ vs $16.7 \%, \mathrm{P}=0.283)$ were treated with sulfonylureas. More than $40.0 \%$ of participants in both groups have a family history of atherosclerotic cardiovascular diseases. Notably, in both groups, baseline levels of Hs-CRP were increased, and no significant differences were found across other risk factors such as total cholesterol, LDL-C, HDL-C and Lp(a) levels in both groups.

\section{Angiographic characteristics and clinical presentations of participants}

As shown in Table 2, participants in Lp-PLA2 elevated group more frequently presented with emergency conditions such as unstable angina and acute myocardial infarction than the normal Lp-PLA2 group (58.5\% vs $55.1 \%$ ). Moreover, the percentage of three vessels stenoses was 
Table 1 Baseline characteristics of participants

\begin{tabular}{|c|c|c|c|}
\hline Variables & $\begin{array}{c}\text { Normal Lp-PLA2 } \\
(n=196)\end{array}$ & $\begin{array}{c}\text { Elevated Lp-PLA2 } \\
(n=130)\end{array}$ & $P$ value \\
\hline Age (years) & $57.4 \pm 11.6$ & $58.3 \pm 13.2$ & 0.115 \\
\hline Male (\%) & $130(66.3)$ & $85(65.4)$ & 0.172 \\
\hline Ever smoking (\%) & 103 (52.6) & $71(54.6)$ & 0.168 \\
\hline HTN (\%) & $105(53.6)$ & $72(55.4)$ & 0.138 \\
\hline DM (\%) & $40(20.4)$ & $28(21.5)$ & 0.144 \\
\hline Family history (\%) & $82(41.8)$ & $58(44.6)$ & 0.126 \\
\hline $\mathrm{BMI}\left(\mathrm{Kg} / \mathrm{m}^{2}\right)$ & $25.4 \pm 2.7$ & $25.6 \pm 2.2$ & 0.278 \\
\hline $\mathrm{CHOL}(\mathrm{mmol} / \mathrm{L})$ & $4.64 \pm 1.08$ & $4.78 \pm 1.12$ & 0.389 \\
\hline LDL-C (mmol/L) & $2.46 \pm 0.79$ & $2.68 \pm 0.93$ & 0.175 \\
\hline $\mathrm{HDL}-\mathrm{C}(\mathrm{mmol} / \mathrm{L})$ & $1.08 \pm 0.36$ & $1.07 \pm 0.33$ & 0.405 \\
\hline Log TG (mmol/L) & $0.17 \pm 0.22$ & $0.15 \pm 0.21$ & 0.141 \\
\hline Lp(a) (mg/dL) & $27.6 \pm 8.4$ & $32.4 \pm 10.5$ & 0.062 \\
\hline CREA (umol/L) & $93.5 \pm 36.4$ & $97.4 \pm 32.8$ & 0.804 \\
\hline BUN (mmol/L) & $6.7 \pm 1.3$ & $7.1 \pm 1.6$ & 0.628 \\
\hline Uric acid (umol/L) & $394.5 \pm 122.5$ & $377.6 \pm 112.8$ & 0.767 \\
\hline $\mathrm{Hs}-\mathrm{CRP}$ (mg/L) & $4.11 \pm 0.92$ & $4.07 \pm 0.86$ & 0.276 \\
\hline Lp-PLA2 (ng/mL) & $123.2 \pm 33.6$ & $336.8 \pm 85.4$ & $<0.001$ \\
\hline LVEF (\%) & $65.4 \pm 12.6$ & $63.8 \pm 10.2$ & 0.446 \\
\hline FS (\%) & $28.5 \pm 3.3$ & $27.2 \pm 3.6$ & 0.308 \\
\hline Anti-DM (\%) & $34(85.0)$ & $24(85.7)$ & 0.147 \\
\hline Anti-HTN (\%) & 98 (93.3) & 67 (93.1) & 0.325 \\
\hline
\end{tabular}

Denote: $\mathrm{HTN}=$ hypertension, $\mathrm{DM}=$ diabetes mellitus, $\mathrm{BMI}=$ body mass index $\mathrm{CHOL}=$ total cholesterol, $\mathrm{TG}=$ triglyceride, $\mathrm{Lp}(\mathrm{a})=$ lipoprotein $(\mathrm{a}), \mathrm{CREA}=$ creatinine, BUN = blood uria nitrogen, $\mathrm{LVEF}=$ left ventricular ejection fraction, $\mathrm{FS}=$ fraction shortening.

higher in elevated Lp-PLA2 group than normal Lp-PLA2 group (40.8\% vs $32.1 \%)$.

\section{Clinical outcome evaluation after 1 year's follow-up}

Approximately $96.0 \%$ (188) and $94.0 \%$ of participants (122) in normal and elevated Lp-PLA2 groups were placed with drug-eluting stents (DES), and the others were with bare-metal stents (BMS). During 1 year's follow-up, all participants were adherent to dual anti-platelet (aspirin

Table 2 Angiographic characteristics and clinical presentations of participants

\begin{tabular}{cccc}
\hline Variables & $\begin{array}{c}\text { Normal Lp-PLA2 } \\
(\mathbf{n}=\mathbf{1 9 6})\end{array}$ & $\begin{array}{c}\text { Elevated Lp-PLA2 } \\
(\mathbf{n}=\mathbf{1 3 0})\end{array}$ & P value \\
\hline UA (\%) & $75(38.3)$ & $56(43.1)$ & 0.042 \\
AMI (\%) & $33(16.8)$ & $20(15.4)$ & 0.177 \\
SA (\%) & $88(44.9)$ & $54(41.5)$ & 0.068 \\
Tri-vessels (\%) & $63(32.1)$ & $53(40.8)$ & 0.016 \\
Left main (\%) & $38(19.4)$ & $24(18.5)$ & 0.183 \\
\hline
\end{tabular}

Denote: $\mathrm{UA}=$ unstable angina, $\mathrm{AMI}=$ acute myocardial infarction, $\mathrm{SA}=$ stable angina. plus clopidogrel) and statins (atorvastatin or rosuvastatin) therapies. Other medications such as beta-receptor blockers, angiotensin-converting enzyme (ACE) inhibitor or angiotensin receptor blocker, and medications for hypertension or glucose control were prescribed accordingly, and no between-group differences were found. The incidence of clinical outcomes was comparable between normal and elevated Lp-PLA2 groups (13.3\% versus $15.4 \%$, $\mathrm{P}=0.172$, see Table 3$)$. Moreover, each pre-specified outcome was further evaluated and only the incidence of restenosis was slightly but significantly higher in elevated Lp-PLA2 group than that of normal Lp-PLA2 group (8.5\% vs $4.6 \%, \mathrm{P}=0.047)$.

\section{Univariate and multivariate analysis for incidence of re-stenosis after 1 year's follow-up and evaluation of synergistic effect}

For further evaluating the value of each parameter for the prediction of re-stenosis after 1 year's stent-placement, univariate and multivariate analyses were conducted. As showed in Table 4, several variables were found associated with re-stenosis after 1 year's stent-placement with univariate analysis. However, with multivariate analysis, after adjustment for variables such as age, smoking, hypertension, total cholesterol, Lp(a), Hs-CRP, anti-platelet and medications for hypertension, only diabetes mellitus, LDL-C and Lp-PLA2 were found increasing hazard ratio for restenosis, whereas statins and medications for diabetes mellitus were found beneficial for reducing the incidence of re-stenosis (See Table 5). Synergistic effects between Lp-PLA2 and other risk factors for re-stenosis were evaluated by Cox proportional hazard regression and all values of $\mathrm{P}$ were higher than 0.05 .

\section{Discussion}

Importantly, our current study shows that increased plasma level of Lp-PLA2 at baseline is associated with an increased risk for re-stenosis after 1 year's stent placement. Moreover, patients with increased Lp-PLA2 level more frequently present with urgent situations such as unstable angina and acute myocardial infarction, which is consistent

Table 3 Clinical outcomes evaluation after 1 year's follow-up

\begin{tabular}{cccc}
\hline Variables & $\begin{array}{c}\text { Normal Lp-PLA2 } \\
(\mathbf{n}=196)\end{array}$ & $\begin{array}{c}\text { Elevated Lp-PLA2 } \\
(\mathbf{n}=130)\end{array}$ & P value \\
\hline $\begin{array}{c}\text { Cardiovascular related } \\
\text { death (\%) }\end{array}$ & $6(3.1)$ & $3(2.3)$ & 0.138 \\
Nonfatal MI (\%) & $5(2.6)$ & $3(2.3)$ & 0.216 \\
Nonfatal Stroke (\%) & $6(3.1)$ & $3(2.3)$ & 0.138 \\
Re-stenosis (\%) & $9(4.6)$ & $11(8.5)$ & 0.047 \\
Total (\%) & $26(13.3)$ & $20(15.4)$ & 0.172 \\
\hline
\end{tabular}

Denote: $\mathrm{MI}=$ myocardial infarction. 
Table 4 Univariate analysis for re-stenosis

\begin{tabular}{|c|c|c|}
\hline Variables & Hazard ratio $(95 \% \mathrm{Cl})$ & $P$ value \\
\hline Age & $1.043(0.906-1.083)$ & 0.091 \\
\hline Male & $1.052(0.922-1.074)$ & 0.106 \\
\hline Smoking & $1.078(1.003-1.125)$ & 0.015 \\
\hline HTN & $1.106(1.018-1.276)$ & 0.021 \\
\hline DM & $1.145(1.056-1.303)$ & 0.007 \\
\hline Family history & $1.008(0.914-1.022)$ & 0.108 \\
\hline $\mathrm{BMl}$ & $1.002(0.967-1.005)$ & 0.455 \\
\hline $\mathrm{CHOL}$ & 1.089 (0.953-1.117) & 0.075 \\
\hline LDL-C & $1.227(1.104-1.420)$ & $<0.001$ \\
\hline $\mathrm{HDL}-\mathrm{C}$ & $0.895(0.806-1.007)$ & 0.303 \\
\hline $\mathrm{TG}$ & $1.007(0.926-1.011)$ & 0.436 \\
\hline $\operatorname{Lp}(a)$ & $1.103(1.048-1.166)$ & 0.014 \\
\hline CREA & $1.012(0.915-1.017)$ & 0.344 \\
\hline BUN & 1.005 (0.933-1.009) & 0.428 \\
\hline Uric acid & 1.017 (0.908-1.032) & 0.447 \\
\hline $\mathrm{Hs}-\mathrm{CRP}$ & $1.168(1.109-1.254)$ & $<0.001$ \\
\hline Lp-PLA2 & $1.233(1.114-1.387)$ & $<0.001$ \\
\hline LVEF & $1.017(0.908-1.032)$ & 0.160 \\
\hline FS & $1.011(0.933-1.019)$ & 0.174 \\
\hline Anti-platelet & $0.826(0.801-0.944)$ & 0.022 \\
\hline Statins & $0.778(0.723-0.806)$ & $<0.001$ \\
\hline Medications for HTN & $0.909(0.886-1.005)$ & 0.096 \\
\hline Medications for DM & $0.845(0.817-0.896)$ & 0.018 \\
\hline
\end{tabular}

Denote: $\mathrm{Cl}=$ confidence interval.

with previous findings that higher Lp-PLA2 level is strongly associated with a higher incidence of plaque rupture and major adverse events $[19,20]$. Additionally, our study also reveals that although a vast majority of patients present with Hs-CRP elevation, increased Hs-CRP level at baseline is not associated with re-stenosis after adjustment for other risk factors, and no synergistic effects between Lp-PLA2 and other risk factors for re-stenosis is found in current study.

Notably, in the past decades, the outcomes of patients with acute coronary syndrome have been significantly improved by stent placement, and with its excellent

Table 5 Multivariate analysis for re-stenosis

\begin{tabular}{ccc}
\hline Variables & Hazard ratio $(\mathbf{9 5 \%} \mathbf{C l})$ & P value \\
\hline DM & $1.078(1.014-1.117)$ & 0.023 \\
LDL-C & $1.165(1.074-1.205)$ & 0.008 \\
Lp-PLA2 & $1.140(1.068-1.195)$ & 0.017 \\
Statins & $0.806(0.788-0.865)$ & 0.032 \\
Medications for DM & $0.837(0.802-0.925)$ & 0.037 \\
\hline
\end{tabular}

features of less invasive and highly efficient, PCI has become the principal therapy for patients with significant CHD [21-23]. However, the incidence of re-stenosis after PCI is still high in spite of prolongation of dual antiplatelet therapy and intensive statin treatment [15,24]. Many mechanisms have been identified responsible for this phenomenon. For example, endothelial dysfunction and activation, smooth muscle cells migration and proliferation, as well as continuous vascular inflammation have been demonstrated that individually and/or simultaneously contribute to in-stent re-stenosis $[25,26]$.

Accordingly, Lp-PLA2 is an enzyme predominantly produced by leukocytes within atherosclerotic plaques and then excretes into circulation system $[27,28]$. It has now been well documented that plasma level of LpPLA2 is highly correlated with the concentration of Lp-PLA2 within the plaques [29]. Therefore, evaluating plasma level of Lp-PLA2 could accurately and promptly reflect the severity of vascular inflammation. Owning to its value of adding prognostic information to traditional risk evaluation algorithm, measurement of Lp-PLA2 has been recommended to patients with moderate or high cardiovascular risk $[18,30]$. However, whether increased plasma level of Lp-PLA2 is associated with an increased risk of re-stenosis after stent-placement is still unclear. For example, the study conducted by Moldoveanu and colleagues showed that there was no significant difference of baseline level of Lp-PLA2 in patients with and without re-stenosis after PCI [31]. Nevertheless, the result in our current study indicated that increased baseline level of Lp-PLA2 portended an increased risk of re-stenosis after 1 year's follow-up. To our best knowledge, there might be some mechanisms contributing to this discrepancy. In the first place, the protocols of these two studies are quite different. In the study conducted by Moldoveanu et al., they divided patients into two groups according to the end-point in terms of with or without in-stent re-stenosis. While in our study, patients were assigned into normal and elevated Lp-PLA2 groups according to their baseline levels. Secondary, the duration of follow-up in the former study was only 6 months, while the patients in our study were followed-up for 1 year. Thirdly, the smaller sample size of Moldoveanu's study might also be a potential reason for the negative finding. In light of the mechanisms associated with restenosis as mentioned above, we believed that the complex roles Lp-PLA2 plays on vessel walls might in part explain our findings. Pathophysiologically, after engulfed by macrophages, oxidative-LDL would be degraded into two major substrates, named lyso-phosphotidylcholine (LysoPC) and oxidized non-esterified fatty acids (oxNEFAs), by Lp-PLA2. Accordingly, Lyso-PC and oxNEFAs have potent effects in recruiting inflammatory cells, promoting platelets activation and aggregation, impairing endothelial 
functions as well as enhancing smooth muscle cells proliferation and migration which subsequently lead to neointima formation and re-stenosis [32-34]. Taken together, it was reasonable to speculate that increased plasma level of Lp-PLA2 was associated with higher risk of re-stenosis. Nevertheless, the study conducted by Turunen and colleagues showed that local adenovirus-mediated Lp-PLA2 gene transfer resulted in a significant reduction in neointima formation in balloon-denuded rabbit aorta [35]. However, the pathophysiology of aorta denudation by balloon was somewhat, if not completely, different from that of vascular inflammation inducing by hyperlipidemia and endothelial dysfunction and activation. Furthermore, a large number of clinical studies have consistently demonstrated the positive relationship between increased plasma level of Lp-PLA2 and adverse clinical outcomes $[8,9,11,20]$. Additionally, as stent placement may stimulate local inflammatory reaction and up-regulate inflammatory cytokines such as tumor necrosis factor-alpha expression, which in turn leads to platelet activating factor and LpPLA2 correspondingly increase. However, since only baseline Lp-PLA2 level has been measured, our study was impossible to make any conclusion that whether the change of platelet activating factor and Lp-PLA2 after stent-placement would also have significant effects on re-stenosis. Furthermore, since the percentages of drug-eluting stent and bare-metal stent placement in the normal and elevated groups were comparable, any bias related to stent-placement might also be excluded. In the future, conducting a prospective research to investigate whether reducing Lp-PLA2 level could decrease the risk of re-stenosis would definitely be a milestone with regard to the new era of CAD therapy.

On the other hand, at the very beginning, Lp-PLA2 was considered as a cardio-protective factor due to its effects on degrading platelet activating factor, a potent substrate in enhancing vascular inflammation and impairing cardiac function [36]. Nevertheless, since the positive relationship between Lp-PLA2 level and increased CVD risk has been firstly reported in WOSCOPS study in 2000 [37], many studies thereafter have consistently corroborated the detrimental effects of Lp-PLA2 on cardiovascular system $[8,38,39]$. Currently, the results from our study also indicated that patient with increased LpPLA2 level appeared to present more severe and urgent condition than that with normal Lp-PLA2 level, which might be partially explained by the adverse effects (expanding necrotic lipid core and thinning fibrous cap) Lp-PLA2 imposes on vessel walls $[8,40]$. The higher percentage of patients with three vessels stenoses in elevated Lp-PLA2 group might also partially reflect the adverse effects Lp-PLA2 exerts on atherogenesis and progression.

Thirdly, due to the production of inflammatory cytokines such as interleukin-6 tumor necrosis factor-alpha and platelet activating factor from adipose tissues, obesity is considered as one of the major risk factor for cardiovascular events such as in-stent re-stenosis $[41,42]$. Interestingly, previous one study showed that increased Lp-PLA2 might compensate for the adiposity-associated increases in inflammatory and oxidative burden [43]. Therefore, it might be reasonable to speculate that in patients with obesity, the incidence of re-stenosis in higher Lp-PLA2 level group might be lower than the lower Lp-PLA2 group. However, in our current study, no significant difference of incidence of re-stenosis was found in obese patients with normal and increased LpPLA2 level (33.3\% vs 36.4\%, P = 0.208).

Finally, since a vast majority of participants in current study were with increased level of $\mathrm{Hs}-\mathrm{CRP}(>3 \mathrm{mg} / \mathrm{L})$, we therefore further evaluated the relationship between Hs-CRP level and re-stenosis. With univariate analysis, Hs-CRP appeared to be a potential predictor for restenosis. Nevertheless, after adjustment for other risk factors, Hs-CRP did not remain independently associated with re-stenosis, which was consistent with previous studies $[44,45]$, in which increased Hs-CRP level before PCI were not associated with in-stent re-stenosis. We believed that this negative finding might be partially due to the unspecific characteristic of Hs-CRP, with respect to Hs-CRP elevation could be confounded by other diseases such as latent and modest infection $[46,47]$. Contrary to Hs-CRP, Lp-PLA2 still remained an independent predictor for restenosis after adjustment for other risk factors (hazard ratio: 1.140, 95\% confidence interval: 1.068-1.195), which we believed was predominantly due to its high specificity for vascular inflammation in the setting of atherosclerotic cardiovascular diseases $[6,14]$. In order to explore any synergistic effect between Lp-PLA2 and other risk factors for re-stenosis, Cox proportional hazard regression were performed and no significant synergism was found which we considered might be partially ascribed to the relatively small sample size of current study and future study is warranted to further investigate whether any synergistic effect exists between traditional risk factor and Lp-PLA2 for restenosis after stent-placement.

\section{Conclusion}

The results of our study indicate that increased plasma level of Lp-PLA2 at baseline is associated with increased risk of re-stenosis after 1 year's stent-placement, and measurement of Lp-PLA2 may be helpful and useful for identifying subjects who are at an increased risk for restenosis. Future study is warranted to investigate whether decreasing plasma level of Lp-PLA2 with specific antagonist will reduce the incidence of re-stenosis.

Competing interests

The authors declare that they have no competing interests. 


\section{Authors' contributions}

$D Z, F Z, H L$ and LL predominantly performed this study, RQ and RX helped to collect the demographic and clinical characteristics of all participants, HL and AC wrote this article, and CX and WM designed this study and WM helped to revise final version of current manuscript. All authors read and approved the final manuscript.

\section{Authors' information}

Dongdan Zheng, FanFang Zeng, Anping Cai: co-first authors.

\section{Acknowledgement}

We appreciate very much for the help of Dr. Shaoqi Rao in assisting the statistic analyses of our results.

\section{Author details}

'Department of Cardiology, The First Affiliated Hospital of Sun Yat-sen University, 58 Zhongshan Road 2, Guangzhou 510080, China. ²Department of Cardiology, Shenzhen Hospital of HongKong University, Shenzhen 518000 China. ${ }^{3}$ Department of Cardiology, Guangdong Cardiovascular Institute, Guangdong General Hospital, Guangdong Academy of Medical Sciences, Guangzhou 510080, China. " Department of Cardiology, The 3rd People's Hospital, Huizhou 516000, China.

Received: 7 January 2014 Accepted: 19 February 2014

Published: 1 March 2014

\section{References}

1. Lloyd-Jones DM: Cardiovascular risk prediction: basic concepts, current status, and future directions. Circulation 2010, 121:1768-1777.

2. Heidenreich PA, Trogdon JG, Khavjou OA, Butler J, Dracup K, Ezekowitz MD, Finkelstein EA, Hong Y, Johnston SC, Khera A, Lloyd-Jones DM, Nelson SA, Nichol G, Orenstein D, Wilson PW, Woo YJ: Forecasting the future of cardiovascular disease in the United States: a policy statement from the American Heart Association. Circulation 2011, 123:933-944.

3. Ross R: Atherosclerosis-an inflammatory disease. N Engl J Med 1999, 340:115-126.

4. Madjid M, Willerson JT: Inflammatory markers in coronary heart disease. Br Med Bull 2011, 100:23-38.

5. Ikonomidis I, Michalakeas CA, Lekakis J, Parissis J, Anastasiou-Nana M: The role of lipoprotein-associated phospholipase A2 (Lp-PLA(2)) in cardiovascular disease. Rev Recent Clin Trials 2011, 6:108-113.

6. Cai A, Zheng D, Qiu R, Mai W, Zhou Y: Lipoprotein-associated phospholipase A2 (Lp-PLA(2)): a novel and promising biomarker for cardiovascular risks assessment. Dis Markers 2013, 34:323-331.

7. Theilmeier G, De Geest B, Van Veldhoven PP, Stengel D, Michiels C, Lox M, Landeloos M, Chapman MJ, Ninio E, Collen D, Himpens B, Holvoet P: $\mathrm{HDL}$-associated PAF-AH reduces endothelial adhesiveness in apoE-/-mice. FASEB J 2000, 14:2032-2039.

8. Wilensky RL, Shi Y, Mohler ER 3rd, Hamamdzic D, Burgert ME, Li J, Postle A Fenning RS, Bollinger JG, Hoffman BE, Pelchovitz DJ, Yang J, Mirabile RC, Webb CL, Zhang L, Zhang P, Gelb MH, Walker MC, Zalewski A, Macphee $\mathrm{CH}$ : Inhibition of lipoprotein-associated phospholipase $A 2$ reduces complex coronary atherosclerotic plaque development. Nat Med 2008 , 14:1059-1066.

9. May HT, Horne BD, Anderson JL, Wolfert RL, Muhlestein JB, Renlund DG, Clarke JL, Kolek MJ, Bair TL, Pearson RR, Sudhir K, Carlquist JF: Lipoproteinassociated phospholipase A2 independently predicts the angiographic diagnosis of coronary artery disease and coronary death. Am Heart J 2006, 152:997-1003.

10. Jenny NS, Solomon C, Cushman M, Tracy RP, Nelson JJ, Psaty BM, Furberg CD: Lipoprotein-associated phospholipase $A(2)(\operatorname{Lp}-\mathrm{PLA}(2))$ and risk of cardiovascular disease in older adults: results from the Cardiovascular Health Study. Atherosclerosis 2010, 209:528-532.

11. Thompson A, Gao P, Orfei L, Watson S, Di AE, Kaptoge S, Ballantyne C, Cannon CP, Criqui M, Cushman M, Hofman A, Packard C, Thompson SG, Collins R, Danesh J: Lipoprotein-associated phospholipase $A(2)$ and risk of coronary disease, stroke, and mortality: collaborative analysis of 32 prospective studies. Lancet 2010, 375:1536-1544.

12. Dohi T, Miyauchi K, Okazaki S, Yokoyama T, Ohkawa R, Nakamura K, Yanagisawa N, Tsuboi S, Ogita M, Yokoyama K, Kurata T, Yatomi Y, Daida H: Decreased circulating lipoprotein-associated phospholipase A2 levels are associated with coronary plaque regression in patients with acute coronary syndrome. Atherosclerosis 2011, 219:907-912.

13. Anderson JL: Lipoprotein-associated phospholipase A2: an independent predictor of coronary artery disease events in primary and secondary prevention. Am J Cardiol 2008, 101:23F-33F.

14. Corson MA, Jones PH, Davidson MH: Review of the evidence for the clinical utility of lipoprotein-associated phospholipase A2 as a cardiovascular risk marker. Am J Cardiol 2008, 101:41F-50F.

15. Cannon CP, Braunwald E, McCabe CH, Rader DJ, Rouleau JL, Belder R, Joyal SV, Hill KA, Pfeffer MA, Skene AM: Intensive versus moderate lipid lowering with statins after acute coronary syndromes. N Engl J Med 2004, 350:1495-1504.

16. Pedersen TR, Faergeman O, Kastelein JJ, Olsson AG, Tikkanen MJ, Holme I, Larsen ML, Bendiksen FS, Lindahl C, Szarek M, Tsai J: High-dose atorvastatin vs usual-dose simvastatin for secondary prevention after myocardial infarction: the IDEAL study: a randomized controlled trial. JAMA 2005, 294:2437-2445

17. Kamstrup PR, Benn M, Tybjaerg-Hansen A, Nordestgaard BG: Extreme lipoprotein(a) levels and risk of myocardial infarction in the general population: the Copenhagen City Heart Study. Circulation 2008, 117:176-184.

18. Davidson MH, Corson MA, Alberts MJ, Anderson JL, Gorelick PB, Jones PH, Lerman A, McConnell JP, Weintraub HS: Consensus panel recommendation for incorporating lipoprotein-associated phospholipase A2 testing into cardiovascular disease risk assessment guidelines. Am J Cardiol 2008, 101:51F-57F

19. Brilakis ES, McConnell JP, Lennon RJ, Elesber AA, Meyer JG, Berger PB: Association of lipoprotein-associated phospholipase A2 levels with coronary artery disease risk factors, angiographic coronary artery disease, and major adverse events at follow-up. Eur Heart J 2005, 26:137-144

20. Kiechl S, Willeit J, Mayr M, Viehweider B, Oberhollenzer M, Kronenberg F, Wiedermann CJ, Oberthaler S, Xu Q, Witztum JL, Tsimikas S: Oxidized phospholipids, lipoprotein(a), lipoprotein-associated phospholipase A2 activity, and 10-year cardiovascular outcomes: prospective results from the Bruneck study. Arterioscler Thromb Vasc Biol 2007, 27:1788-1795.

21. Tanaka A, Imanishi T, Kitabata H, Kubo T, Takarada S, Tanimoto T, Kuroi A, Tsujioka H, Ikejima H, Komukai K, Kataiwa H, Okouchi K, Kashiwaghi M, Ishibashi K, Matsumoto H, Takemoto K, Nakamura N, Hirata K, Mizukoshi M, Akasaka T: Lipid-rich plaque and myocardial perfusion after successful stenting in patients with non-ST-segment elevation acute coronary syndrome: an optical coherence tomography study. Eur Heart J 2009, 30:1348-1355.

22. Mega $J$, Simon T, Collet JP, Anderson JL, Antman EM, Bliden K, Cannon CP, Danchin N, Giusti B, Gurbel P, Horne BD, Hulot JS, Kastrat A, Montalescot G, Neumann FJ, Shen L, Sibbing D, Steg PG, Trenk D, Wiviott SD, Sabatine MS: Reduced-function CYP2C19 genotype and risk of adverse clinical outcomes among patients treated with clopidogrel predominantly for PCl: a meta-analysis. JAMA 2010, 304:1821-1830.

23. Sorajja P, Gersh BJ, Cox DA, McLaughlin MG, Zimetbaum P, Costantini C, Stuckey T, Tcheng JE, Mehran R, Lansky AJ, Grines CL, Stone GW: Impact of delay to angioplasty in patients with acute coronary syndromes undergoing invasive management: analysis from the ACUITY (Acute Catheterization and Urgent Intervention Triage strategY) trial. J Am Coll Cardiol 2010, 55:1416-1424.

24. LaRosa JC, Grundy SM, Waters DD, Shear C, Barter P, Fruchart JC, Gotto AM Greten H, Kastelein JJ, Shepherd J, Wenger NK: Intensive lipid lowering with atorvastatin in patients with stable coronary disease. N Engl J Med 2005, 352:1425-1435.

25. Breen DM, Dolinsky W, Zhang H, Ghanim H, Guo J, Mroziewicz M, Tsiani EL, Bendeck MP, Dandona P, Dyck JR, Heximer SP, Giacca A: Resveratrol inhibits neointimal formation after arterial injury through an endothelial nitric oxide synthase-dependent mechanism. Atherosclerosis 2012, 222:375-381.

26. Park SJ, Kang SJ, Virmani R, Nakano M, Ueda Y: In-stent neoatherosclerosis: a final common pathway of late stent failure. J Am Coll Cardiol 2012, 59:2051-2057

27. Packard CJ: Lipoprotein-associated phospholipase A2 as a biomarker of coronary heart disease and a therapeutic target. Curr Opin Cardiol 2009, 24:358-363. 
28. Rosenson RS: Phospholipase A2 inhibition and atherosclerotic vascular disease: prospects for targeting secretory and lipoprotein-associated phospholipase A2 enzymes. Curr Opin Lipidol 2010, 21:473-480.

29. Colley KJ, Wolfert RL, Cobble ME: Lipoprotein associated phospholipase $\mathrm{A}(2)$ : role in atherosclerosis and utility as a biomarker for cardiovascular risk. EPMA J 2011, 2:27-38.

30. Third Report of the National Cholesterol Education Program (NCEP) Expert Panel on Detection, Evaluation, and Treatment of High Blood Cholesterol in Adults (Adult Treatment Panel III) final report. Circulation 2002, 106:3143-3421.

31. Moldoveanu E, Mut-Vitcu B, Tanaseanu GR, Marta DS, Manea G, Kosaka T, Vidulescu C, Tanaseanu C: Low basal levels of circulating adiponectin in patients undergoing coronary stenting predict in-stent restenosis, independently of basal levels of inflammatory markers: lipoprotein associated phospholipase A2, and myeloperoxidase. Clin Biochem 2008, 41:1429-1433.

32. Boffa MB, Marcovina SM, Koschinsky ML: Lipoprotein(a) as a risk factor for atherosclerosis and thrombosis: mechanistic insights from animal models. Clin Biochem 2004, 37:333-343.

33. Tsimikas S, Tsironis LD, Tselepis AD: New insights into the role of lipoprotein(a)-associated lipoprotein-associated phospholipase A2 in atherosclerosis and cardiovascular disease. Arterioscler Thromb Vasc Biol 2007, 27:2094-2099.

34. Garg PK, McClelland RL, Jenny NS, Criqui M, Liu K, Polak JF, Jorgensen NW, Cushman M: Association of lipoprotein-associated phospholipase A(2) and endothelial function in the Multi-Ethnic Study of Atherosclerosis (MESA). Vasc Med 2011, 16:247-252.

35. Turunen P, Puhakka H, Rutanen J, Hiltunen MO, Heikura T, Gruchala M, Yla-Herttuala S: Intravascular adenovirus-mediated lipoprotein-associated phospholipase A2 gene transfer reduces neointima formation in balloon-denuded rabbit aorta. Atherosclerosis 2005, 179:27-33.

36. Detopoulou P, Nomikos T, Fragopoulou E, Chrysohoou C, Antonopoulou S: Platelet Activating Factor in Heart Failure: Potential Role in Disease Progression and Novel Target for Therapy. Curr Heart Fail Rep 2013, 10:122-129.

37. Packard CJ, O'Reilly DS, Caslake MJ, McMahon AD, Ford I, Cooney J, Macphee CH, Suckling KE, Krishna M, Wilkinson FE, Rumley A, Lowe GD: Lipoprotein-associated phospholipase A2 as an independent predictor of coronary heart disease. West of Scotland Coronary Prevention Study Group. N Engl J Med 2000, 343:1148-1155.

38. Blankenberg S, Stengel D, Rupprecht HJ, Bickel C, Meyer J, Cambien F, Tiret L, Ninio E: Plasma PAF-acetylhydrolase in patients with coronary artery disease: results of a cross-sectional analysis. J Lipid Res 2003, 44:1381-1386

39. Garza CA, Montori VM, McConnell JP, Somers VK, Kullo IJ, Lopez-Jimenez F Association between lipoprotein-associated phospholipase A2 and cardiovascular disease: a systematic review. Mayo Clin Proc 2007, 82:159-165

40. Kougias $P$, Chai $H$, Lin $P H$, Lumsden $A B$, Yao $Q$, Chen $C$ : Lysophosphatidylcholine and secretory phospholipase A2 in vascular disease: mediators of endothelial dysfunction and atherosclerosis. Med Sci Monit 2006, 12:RA5-RA16.

41. Takeda R, Suzuki E, Satonaka H, Oba S, Nishimatsu H, Omata M, Fujita $T$, Nagai R, Hirata Y: Blockade of endogenous cytokines mitigates neointimal formation in obese Zucker rats. Circulation 2005, 111:1398-1406.

42. Miao CY, Li ZY: The role of perivascular adipose tissue in vascular smooth muscle cell growth. Br J Pharmacol 2012, 165:643-658

43. Detopoulou P, Nomikos T, Fragopoulou E, Panagiotakos DB, Pitsavos C, Stefanadis C, Antonopoulou S: Lipoprotein-associated phospholipase A2 (Lp-PLA2) activity, platelet-activating factor acetylhydrolase (PAF-AH) in leukocytes and body composition in healthy adults. Lipids Health Dis 2009, 8:19

44. Segev A, Kassam S, Buller CE, Lau HK, Sparkes JD, Connelly PW, Seidelin PH, Natarajan MK, Cohen EA, Strauss BH: Pre-procedural plasma levels of C-reactive protein and interleukin- 6 do not predict late coronary angiographic restenosis after elective stenting. Eur Heart J 2004, 25:1029-1035.

45. Delhaye C, Sudre A, Lemesle G, Marechaux S, Broucqsault D, Hennache B, Bauters C, Lablanche JM: Preprocedural high-sensitivity C-reactive protein predicts death or myocardial infarction but not target vessel revascularization or stent thrombosis after percutaneous coronary intervention. Cardiovasc Revasc Med 2009, 10:144-150.

46. Ballantyne $\mathrm{CM}$, Nambi V: Markers of inflammation and their clinical significance. Atheroscler Supp/ 2005, 6:21-29.

47. Elkind MS, Tai W, Coates K, Paik MC, Sacco RL: High-sensitivity C-reactive protein, lipoprotein-associated phospholipase $\mathrm{A} 2$, and outcome after ischemic stroke. Arch Intern Med 2006, 166:2073-2080.

doi:10.1186/1476-511X-13-41

Cite this article as: Zheng et al:: Baseline elevated Lp-PLA2 is associated with increased risk for re-stenosis after stent placement. Lipids in Health and Disease 2014 13:41.

\section{Submit your next manuscript to BioMed Central and take full advantage of:}

- Convenient online submission

- Thorough peer review

- No space constraints or color figure charges

- Immediate publication on acceptance

- Inclusion in PubMed, CAS, Scopus and Google Scholar

- Research which is freely available for redistribution

Submit your manuscript at www.biomedcentral.com/submit
C BioMed Central 